\title{
FORMULATION OF FLUCONAZOLE AS TOPICAL ANTIFUNGAL GELS BY MICROSPONGE BASED DELIVERY SYSTEMS
}

\author{
Swamykannu Dineshmohan ${ }^{1} *$, Vangadari Rama Mohan Gupta ${ }^{2}$
}

\author{
1Department of \\ Pharmaceutics, Vishnu \\ Institute of Pharmaceutical \\ Education and Research, \\ Narsapur, Hyderabad, \\ 502313. India \\ 2Department of \\ Pharmaceutics, Pullareddy \\ Institute of Pharmacy, \\ Annaram, Hyderabad, \\ 502313. India
}

Submitted: 02-03-2017

Revised: $10-05-2017$

Accepted: $12-06-2017$

${ }^{*}$ Corresponding author

S. Dineshmohan

Email:

dineshmohan.s@viper.ac.in

\begin{abstract}
The purpose of present work was to formulate fluconazole loaded microsponge-based topical delivery system for modified release. Microsponges with varied drug-polymer ratios were prepared by emulsion solvent diffusion technique using ethyl cellulose as release retard material. Prepared microsponges were studied for particle size and physical characterization. Scanning Electron Microscopy (SEM) images showed the microsponges porous and spherical in shape. The microsponges were then incorporated in carbopol gel and evaluated for $\mathrm{pH}$, viscosity, spreadability, drug content, in vitro release. The In vitro drug release showed that microsponges with 1:1.5 drug-polymer ratios (F3) were more efficient to give sustained release of $74.2 \%$ at the end of $8 \mathrm{~h}$. All the microsponge gel formulations (i.e.F1-F10) showed better results like $\mathrm{pH}$ between 6.5-7.0, viscosity between $25,030-47,390 \mathrm{cps}$, spreadability $2-4 \mathrm{~cm} / \mathrm{s}$ and drug content of $76.20 \pm 0.02 \%$ to $96.41 \pm 0.01 \%$. Hence, the fabricated microsponge based formulation of fluconazole would be anticipation and promising substitute to conventional therapy of skin infections.
\end{abstract}

Keywords: Fluconazole, microsponge, ethyl cellulose, SEM

\section{INTRODUCTION}

Fluconazole is a synthetic antifungal agent belonging to the group of triazole. It is one of the commonly used antifungal agents for most kinds of fungal infections including superficial and invasive fungal infections (Vinod et al., 2012). Regrettably fluconazole oral administration has limitations such as nausea, vomiting, bloating and abdominal discomfort. Alongside most of the time the parenteral administration of fluconazole led to skin rashes and itching (Doaa et al., 2012). For these reasons, now a day's advance localized and transdermal delivery has gained a lot of importance (Niethard et al., 2005; Kulkarni et al., 2011). The conventional gel formulation of fluconazole causes cutaneous irritation and prolonged use led to dermal hypersensitivity. So, a novel system necessitates which will increase the presence of active agents either on skin surface or within epidermis, concurrently reducing hasty transdermal penetration. Many researchers have attempted to develop novel transdermal formulations of fluconazole. Accordingly, the goal of our research is to formulate and evaluate fluconazole microsponge loaded carbopol gel for safe, effective and stable gel and evaluate the in-vitro sustained release performance. Microspongebased delivery systems (MDS) give assurance of drug localization on skin surface and within epidermis without entering in systemic circulation in greater extent; thereby reducing systemic and local cutaneous adversities. They also offer an advantage of programmable release and are biologically safe. Additionally, this technology presents quite a lot of benefits via drug entrapment by means of better formulation flexibility, abridged side effects, improved elegance and superior stability (D'souza and More, 2008; Vyas et al., 2010; Vyas and Khar, 2002; Won, 1987).

\section{MATERIALS AND METHODS}

Fluconazole was obtained as a gift sample from RMS Research labs Pvt Ltd Hyderabad, India. Ethyl cellulose was gifted by Yeluri formulations, Hyderabad, India. Polyvinyl alcohol, triethyl citrate and ethyl acetate were purchased from Emerck (India) Ltd., Mumbai. All other chemicals and solvents used are of analytical grade. 
Table I. Composition of fluconazole microsponges

\begin{tabular}{|c|c|c|c|c|c|c|c|c|c|c|c|}
\hline \multirow{2}{*}{\multicolumn{2}{|c|}{ S.No Ingredients }} & \multicolumn{10}{|c|}{ Formulation batches of fluconazole microsponge } \\
\hline & & F1 & F2 & F3 & F4 & F5 & F6 & F7 & F8 & F9 & F10 \\
\hline 1 & $\mathrm{D} / \mathrm{P}$ ratio & $1: 0.5$ & $1: 1$ & $1: 1.5$ & $1: 2$ & $1: 2.5$ & $1: 3$ & $1: 1.5$ & $1: 1.5$ & $1: 1.5$ & $1: 1.5$ \\
\hline 2 & Ethyl acetate $(\mathrm{mL})$ & 10 & 10 & 10 & 10 & 10 & 10 & 10 & 10 & 10 & 10 \\
\hline 3 & Triethyl citrate $(\mathrm{mL})$ & 1 & 1 & 1 & 1 & 1 & 1 & 1 & 1 & 1 & 1 \\
\hline 4 & PVA (\%w/v) & 0.75 & 0.75 & 0.75 & 0.75 & 0.75 & 0.75 & 0.45 & 0.6 & 0.9 & 1 \\
\hline 5 & Water $(\mathrm{mL})$ & 90 & 90 & 90 & 90 & 90 & 90 & 90 & 90 & 90 & 90 \\
\hline
\end{tabular}

$\mathrm{D} / \mathrm{P}$ ratio $=$ Drug: Polymer ratio

All the microsponge formulations were prepared using emulsion solvent diffusion method (Orlu et al., 2006). In this experiment required an amount of ethyl cellulose and triethyl citrate were dissolved in ethyl acetate (EA) further fluconazole was added and stirred well. EA was noticed as an effective solvent for dissolving both the drug and the polymer. The EA solution was gradually added in $25 \mathrm{~mL}$ of an aqueous solution of poly vinyl alcohol (PVA) at room temperature with continuous stirring. Then the final mixture was filtered through filter paper with a pore size of $0.45 \mu \mathrm{m}$ to separate formed microsponges and dried at room temperature (Table I).

\section{Characterization of microsponge formulations Fourier Transform Infrared (FT-IR) Studies}

IR spectra of the pure drug, other excipients and formulations were obtained and compared. In the present study, potassium bromide $(\mathrm{KBr})$ pellet method was employed. The samples were thoroughly mixed with dry powder of potassium bromide and scanned from $4000-400 \mathrm{~cm}^{-1}$ by FT-IR spectrophotometer (Model number 02437 Shimadzu, India)

\section{Scanning electron microscopy}

The morphology and appearance of the microsponges were studied using SEM (SEMJEOL Instrument, JSM- 6360, Japan) operating at $15 \mathrm{kV}$. The samples were dusted onto doublesided tape on a metal stub and coated with gold/palladium alloy under vacuum. The obtained photograph was recorded at $\mathrm{x} 400$ magnification (Nokhodchi et al., 2007).

\section{Production yield actual FLZ content, and entrapment efficiency (EE \%) \\ The production yield (PY) was} determined by following formula (Kilicarslan and Baykara, 2003; Mine et al., 2006.) accurately calculating the initial weight of the raw materials and the weight of the obtained microsponge particles. Samples of drug loaded microsponges $(20 \mathrm{mg}$ ) were dissolved in $10 \mathrm{~mL}$ phosphate buffer $\mathrm{pH} 5.5$ under sonication for $20 \mathrm{~min}$ at $25^{\circ} \mathrm{C}$. The samples were filtered using $0.45 \mu \mathrm{m}$ membrane filter and analyzed for FLZ content spectrophotometrically using Shimadzu UV-1650 UV-VIS double beam spectrophotometer (Shimadzu, Japan) at $260 \mathrm{~nm}$. The actual drug content and EE were calculated as given below.

The actual drug content $(\%)=\frac{\mathrm{M}_{\text {act }}}{\mathrm{M}_{m s}} \times 100$

The EE (\%) was calculated according to the following equation:

Entrapment efficiency $=\frac{\mathrm{M}_{a c t}}{\mathrm{M}_{t b e}} \times 100$

Where $\mathrm{M}_{\text {act }}$ is the actual FLZ content in the weighed quantity of the microsponge, $\mathrm{M}_{m s}$ is the weighed quantity of powder of microsponges, and $\mathrm{M}_{\text {the }}$ is the theoretical amount of FLZ in microsponge calculated from the quantity added during preparation. All the experiments were performed in triplicate and the mean of the values was reported.

\section{Particle size analysis}

Particle size analysis of prepared microsponges was carried out using particle size analyzer (Malvern Mastersizer Hydro 2000, Ver.5.54 Malvern, UK) which allows sample 
measurement in the range of $0.020-2000 \mathrm{~mm}$ and the particle refractive index was set to 1.520. Microsponges were dispersed in double distilled water before running the sample in the instrument to ensure that light scattering signal (as indicated by particles count per second) is within the sensitivity range of the instrument.

\section{Preparation of fluconazole microsponge gel}

For preparing fluconazole microsponge gel, $0.5 \mathrm{~g}$ of carbopol 940 was uniformly dispersed in beakers containing sufficient quantity of water and was allowed to hydrate overnight. Then it was mixed with $5 \mathrm{~g}$ of glycerin with methyl paraben to form a paste. Next, $95 \mathrm{~mL}$ of water was added slowly to paste under constant stirring, followed by drop wise triethanolamine addition to adjusting $\mathrm{pH}$ to 6.5-7.5. A calculated amount of FLZ microsponge was incorporated which makes the final concentration of FLZ in the gel is $1 \%$ $\mathrm{w} / \mathrm{w}$.

\section{Evaluation of fluconazole microsponge loaded carbopol gel}

Following evaluation studies of fluconazole microsponge loaded carbopol gel was done by already established methods.

\section{Visual inspection}

The organoleptic properties such as color, texture, consistency, homogeneity and physical appearance of gels containing microsponges were checked by visual observation.

\section{pH measurement}

The $\mathrm{pH}$ of the prepared fluconazole loaded microsponge gel was measured using $\mathrm{pH}$ - meter by putting the tip of the electrode into the gel and after $2 \mathrm{~min}$ the result was recorded (Farhan et al., 2008).

\section{Spreadability}

A sample of $0.1 \mathrm{~g}$ of the gel was pressed between 2 slides with $500 \mathrm{~g}$ weights and left for about $5 \mathrm{~min}$ where no more spreading was expected. Diameters of spread circles were measured in $\mathrm{cm}$ and were taken as comparative values for spreadability (diameter of the spread circle-initial diameter (El-Houssieny and Hamouda, 2010).
$\mathrm{S}=\frac{M L}{\mathrm{~T}} \times 100$

Where $M=$ weight (in $g$ ) attached to the upper slide, $L=$ length (in $\mathrm{cm}$ ) of glass slides, and $T=$ time (in s) taken to separate the slides.

Wooden block-glass slide apparatus was used and by applying weight about $20 \mathrm{~g}$, time for complete separation of upper slide (movable) from lower slide (fixed) was estimated

\section{Viscosity measurement}

Rheology includes the measurement of viscosity, which indicates the resistance of a fluid to flow. The viscosity of gel was determined by using Myr Rotational (cup and bop) digital viscometer with spindle no. R7 with optimum speeds 2.5, 3, 4, 5, 6, 10, $12 \mathrm{rpm}$ at room temperature (Roaa et al., 2014).

\section{In vitro drug release}

The in vitro release of gel formulations was studied using franz diffusion cells. The cellophane membrane $(0.45 \mu \mathrm{m})$ previously soaked overnight in dissolution medium was mounted onto franz diffusion cell with $15 \mathrm{~mL}$ receptor compartment and effective diffusion area $2.84 \mathrm{cF} 2$. PBS ( $\mathrm{pH} 7.4)$ was used as receptor medium, and the system was thermostatically set to $37 \pm 1^{\circ} \mathrm{C}$ under constant stirring. $2 \mathrm{~g}$ of microsponge from each batch were conducted for the diffusion study. Aliquots of $1 \mathrm{~mL}$ volume were withdrawn at specific time intervals by maintaining sink condition. Withdrawn aliquots were then diluted using receptor medium and analyzed by a UV spectrophotometer (Shimadzu 1601, Kyoto, Japan) at 260nm against PBS pH 7.4. To reveal drug release mechanism and to contrast, release profiles disparities among formulations, data obtained from timely drug release were used. Further, release data were analyzed by means of diverse mathematical models to know release kinetics (Zaki et al., 2011).

\section{Drug release kinetics}

To analyze the mechanism of fluconazole release from the formulations, the in vitro release data were fitted into various release kinetic models. The models used are: zero order, first order, Higuchi model and 


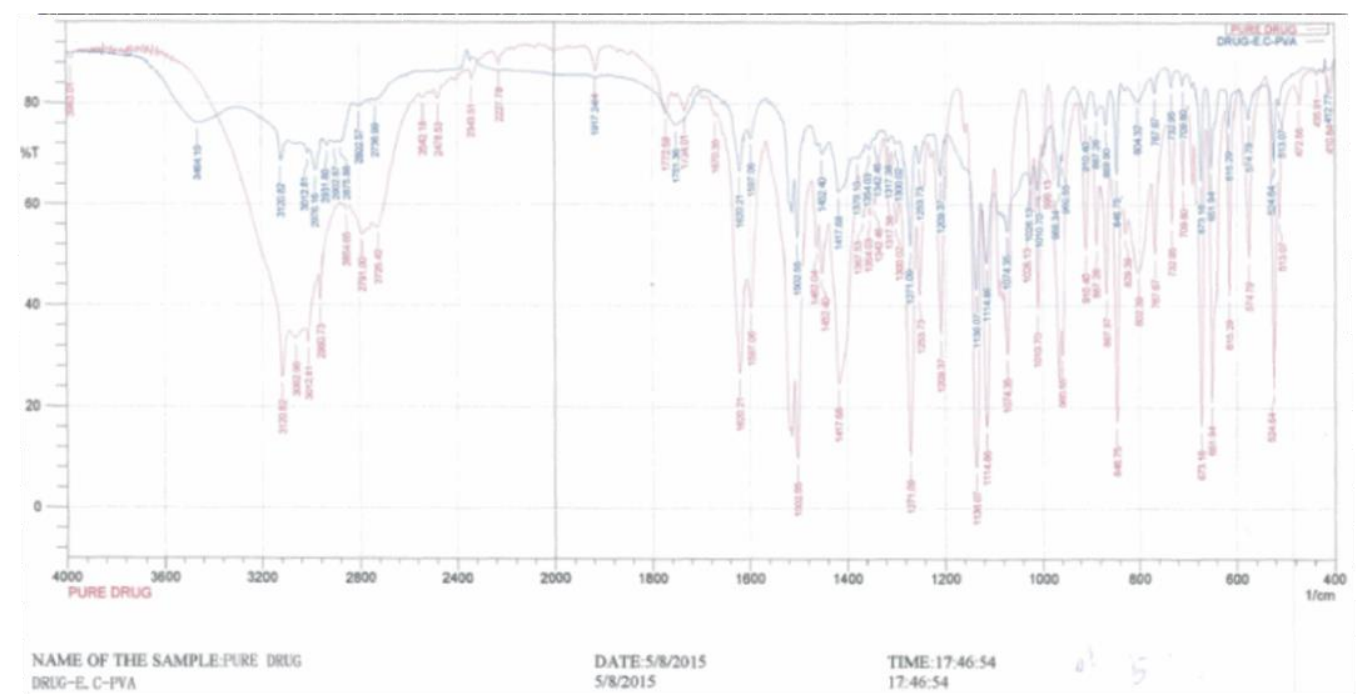

Figure 1. FTIR Spectra of pure drug and phsical mixtures
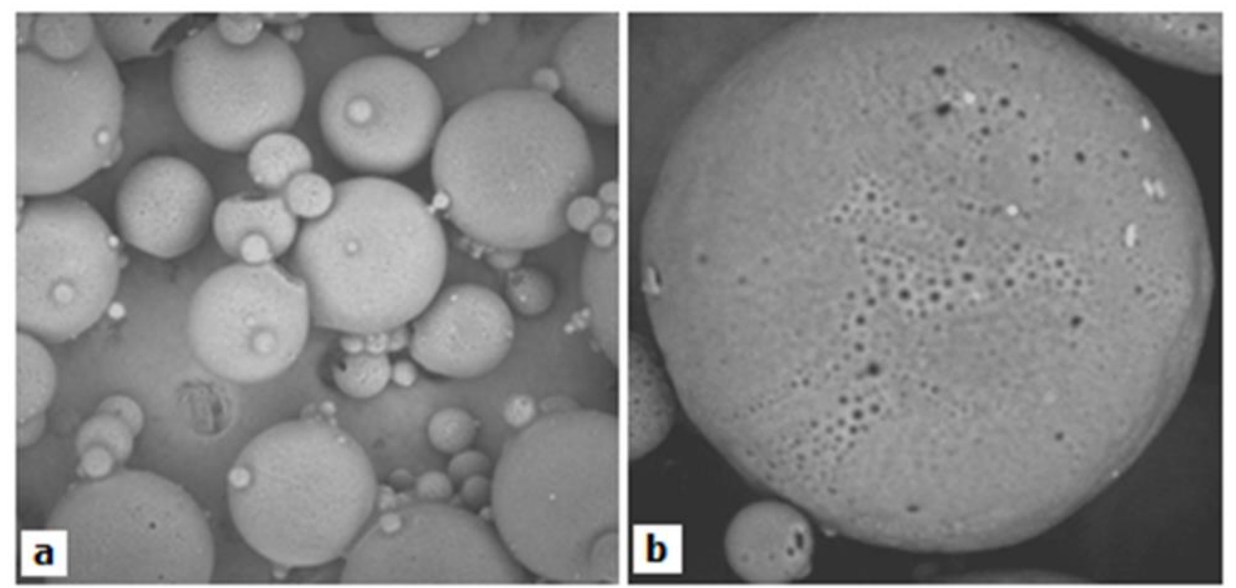

Figure 2. a. SEM of fluconazole loaded microsponges under $\times 400$. b Image of pores on microsponge surface under $\times 400$

Korsmeyer - Peppas (Costa and Lobo, 2001). The model with the highest correlation coefficient was considered to be the best fitted model.

\section{Stability study}

Optimized gel formulation was subjected to stability testing as per ICH. The gel was filled in clean collapsible aluminum tubes and kept at $40^{\circ} \mathrm{C}$ and $75 \% \mathrm{RH}$ in a humidity chamber. The gel was assessed for change in appearance, $\mathrm{pH}$ or in vitro release profile at an interval of $0,15,30,60$ and 90 days.

\section{RESULTS AND DISCUSSIONS} Fourier Transform Infrared (FT-IR)

The IR spectra of pure fluconazole and formulation are shown in figure and table. The peak at $3120 \mathrm{~cm}^{-1}$ indicates $\mathrm{O}-\mathrm{H}$ stretching, $3012 \mathrm{~cm}^{-1}$ for the C-H stretching, $1620 \mathrm{~cm}^{-1}$ for the aromatic $\mathrm{C}=\mathrm{C}$ stretching, $1597 \mathrm{~cm}^{-1}$ for the N-H bending, $1354 \mathrm{~cm}^{-1}$ for the $\mathrm{C}-\mathrm{H}$ bending. These are the major spectral peaks of the drug. All these peaks were present in the formulations and thus this confirms that the drug did not have any interaction with the excipients (Figures 1 and Table II). 
Table II. Actual drug content, encapsulation efficiency and production yield

\begin{tabular}{cccccc}
\hline Code & $\mathbf{D} / \mathbf{P}$ ratio & $\begin{array}{c}\text { Theoretical } \\
\text { drug } \\
\text { content (\%) }\end{array}$ & $\begin{array}{c}\text { Actual drug } \\
\text { content (\%) } \\
\mathbf{\pm} \text { SD }\end{array}$ & $\begin{array}{c}\text { Encapsulation } \\
\text { efficiency } \\
\mathbf{( \% )} \pm \text { SD }\end{array}$ & $\begin{array}{c}\text { Production } \\
\text { yield (\%) } \pm \text { SD }\end{array}$ \\
\hline F1 & $1: 0.5$ & 75 & $72.58 \pm 0.01$ & $85.56 \pm 0.01$ & $32.12 \pm 0.21$ \\
F2 & $1: 1$ & 60 & $58.02 \pm 0.02$ & $85.12 \pm 0.02$ & $34.60 \pm 0.20$ \\
F3 & $1: 1.5$ & 53 & $50.46 \pm 0.01$ & $84.10 \pm 0.03$ & $38.40 \pm 0.39$ \\
F4 & $1: 2$ & 41 & $37.23 \pm 0.14$ & $83.42 \pm 0.01$ & $40.00 \pm 0.01$ \\
F5 & $1: 2.5$ & 36 & $32.16 \pm 0.02$ & $82.10 \pm 0.03$ & $45.13 \pm 0.04$ \\
F6 & $1: 3$ & 28 & $30.16 \pm 0.02$ & $80.10 \pm 0.03$ & $52.24 \pm 0.02$ \\
F7 & $1: 1.5$ & 53 & $49.35 \pm 0.01$ & $89.37 \pm 0.21$ & $77.61 \pm 0.02$ \\
F8 & $1: 1.5$ & 53 & $49.27 \pm 0.02$ & $82.62 \pm 0.01$ & $37.52 \pm 0.11$ \\
F9 & $1: 1.5$ & 53 & $49.83 \pm 0.01$ & $46.12 \pm 0.02$ & $23.31 \pm 0.17$ \\
F10 & $1: 1.5$ & 53 & $51.13 \pm 0.02$ & $49.10 \pm 0.01$ & $21.64 \pm 0.15$ \\
\hline
\end{tabular}

Table III. Kinetic data analysis of optimized microsponge formulation

\begin{tabular}{cccccccc}
\hline \multicolumn{2}{c}{ Zero order } & \multicolumn{2}{c}{ First order } & \multicolumn{2}{c}{ Krose meyer } & \multicolumn{2}{c}{ Higuchi } \\
\hline $\begin{array}{c}\text { Time in } \\
\text { (Hr) }\end{array}$ & $\begin{array}{c}\text { Cum \% } \\
\text { Release in (Hr) }\end{array}$ & $\begin{array}{c}\text { Time } \\
\text { Log Cum \% } \\
\text { Remaining }\end{array}$ & Log of time & $\begin{array}{c}\text { Log cum. } \\
\text { \%release }\end{array}$ & $\begin{array}{c}\text { Sqrt. of } \\
\text { time }\end{array}$ & $\begin{array}{c}\text { Cum \% } \\
\text { drug } \\
\text { release }\end{array}$ \\
\hline 1 & 27.5 & 1 & 1.860338007 & 0 & 1.439332694 & 1 & 27.5 \\
2 & 31.9 & 2 & 1.833147112 & 0.301029996 & 1.503790683 & 1.414213562 & 31.9 \\
3 & 36.3 & 3 & 1.804139432 & 0.477121255 & 1.559906625 & 1.732050808 & 36.3 \\
4 & 42.7 & 4 & 1.758154622 & 0.602059991 & 1.630427875 & 2 & 42.7 \\
5 & 48.6 & 5 & 1.710963119 & 0.698970004 & 1.686636269 & 2.236067977 & 48.6 \\
6 & 57.3 & 6 & 1.630427875 & 0.77815125 & 1.758154622 & 2.449489743 & 57.3 \\
7 & 65.8 & 7 & 1.534026106 & 0.84509804 & 1.81822894 & 2.645751311 & 65.8 \\
8 & 74.2 & 8 & 1.411619706 & 0.903089987 & 1.870403905 & 2.828427125 & 74.2 \\
\hline
\end{tabular}

Table IV. Effect of external phase

\begin{tabular}{ccccc}
\hline Code & $\begin{array}{c}\text { PVA Concentration } \\
\text { in }(\mathbf{m g})\end{array}$ & $\begin{array}{c}\text { Production yield } \\
\mathbf{( \% )} \pm \mathbf{S D}\end{array}$ & $\begin{array}{c}\text { Encapsulation } \\
\text { efficiency } \mathbf{( \% )} \pm \mathbf{S D}\end{array}$ & \% CDR \pm SD \\
\hline F3 & 0.75 & $38.40 \pm 0.39$ & $84.10 \pm 0.03$ & $74.2 \pm 0.46$ \\
F7 & 0.45 & $77.61 \pm 0.02$ & $89.37 \pm 0.21$ & $73.7 \pm 0.29$ \\
F8 & 0.60 & $37.52 \pm 0.11$ & $82.62 \pm 0.01$ & $71.4 \pm 0.23$ \\
F9 & 0.90 & $23.31 \pm 0.17$ & $46.12 \pm 0.02$ & $68.1 \pm 0.27$ \\
F10 & 1.00 & $21.64 \pm 0.15$ & $49.10 \pm 0.01$ & $66.2 \pm 0.32$ \\
\hline
\end{tabular}

Table V. Effect of D/P ratio

\begin{tabular}{cccccc}
\hline Code & $\begin{array}{c}\text { D/P } \\
\text { ratio }\end{array}$ & $\begin{array}{c}\text { Production } \\
\text { yield (\%) } \pm \text { SD }\end{array}$ & $\begin{array}{c}\text { Drug content } \\
\mathbf{( \% )} \pm \mathbf{S D}\end{array}$ & $\begin{array}{c}\text { Encapsulation } \\
\text { efficiency (\%) } \pm \text { SD }\end{array}$ & $\begin{array}{c}\% \\
\text { CDR } \pm \text { SD }\end{array}$ \\
F1 & $1: 0.5$ & $32.12 \pm 0.21$ & $72.58 \pm 0.01$ & $85.56 \pm 0.01$ & $94.1 \pm 0.01$ \\
F2 & $1: 1$ & $34.60 \pm 0.20$ & $58.02 \pm 0.02$ & $85.12 \pm 0.02$ & $85.1 \pm 0.01$ \\
F3 & $1: 1.5$ & $38.40 \pm 0.39$ & $50.46 \pm 0.01$ & $84.10 \pm 0.03$ & $74.2 \pm 0.02$ \\
F4 & $1: 2$ & $40.00 \pm 0.01$ & $37.23 \pm 0.14$ & $83.42 \pm 0.01$ & $65.1 \pm 0.01$ \\
F5 & $1: 2.5$ & $45.13 \pm 0.04$ & $32.16 \pm 0.02$ & $82.10 \pm 0.03$ & $52.8 \pm 0.03$ \\
F6 & $1: 3$ & $52.24 \pm 0.02$ & $30.16 \pm 0.02$ & $80.10 \pm 0.03$ & $42.7 \pm 0.02$ \\
\hline
\end{tabular}




\section{Scanning electron microscopy}

The morphology of the prepared microsponges was studied by SEM analysis. The shape and surface characteristics of the microsponges are shown in (Figure 2) the microsponges were finely spherical and uniform in shape, highly porous in nature. The pores were created by diffusion of solvent from the surface of microsponges. The captured SEM images of microsponges are shownin (Figure 2).

\section{Production yield actual FLZ content, and entrapment efficiency (EE \%)}

The effect of $\mathrm{D} / \mathrm{P}$ ratio of production yield, encapsulation efficiency and drug content (Table III). It revealed that drug encapsulation efficiency did not attain 100\%, this might be due to several quantity of drug gets dissolved in either phase. The production yield of all batches of fluconazole microsponges was ranged from $20.12 \%$ to $74.24 \%$. The D/P ratio and PVA concentration were found to affect production yield significantly. Low production yield was noticed in $\mathrm{D} / \mathrm{P}$ ratio of 1:0.5 (F1), whereas, in $\mathrm{D} / \mathrm{P}$ ratio $1: 3(\mathrm{~F} 6)$ production yield was remarkably high i.e. $74.24 \%$. The results indicated that higher the $\mathrm{D} / \mathrm{P}$ ratio, higher the production yields. At higher drug/polymer ratios, the rate of solvent diffusion from the internal to organic phase decreased due to the higher viscosity of the internal phase (Lee et al., 1999). This provided more time for droplet formation and improved the yield of microsponges besides this; the concentration of surfactant required to bring about the formation of uniform microsponges was found to be $0.75 \% \mathrm{w} / \mathrm{v}$ as illustrated in (Table I). The encapsulation efficiencies were in the range of $64.12-91.35 \%$ (Table III). The outcome of encapsulation efficiency reflected that increasing the $\mathrm{D} / \mathrm{P}$ ratios $(\mathrm{F} 1-\mathrm{F} 6)$ led to decrease drug loadings.

\section{Particle size}

The average particle size of microsponge formulations should be in the range of 5$300 \mu \mathrm{m}$. The Optimized batch F3 has been found with particle size was corresponding to 108.16 $\mu \mathrm{m}$ (Figure 3).

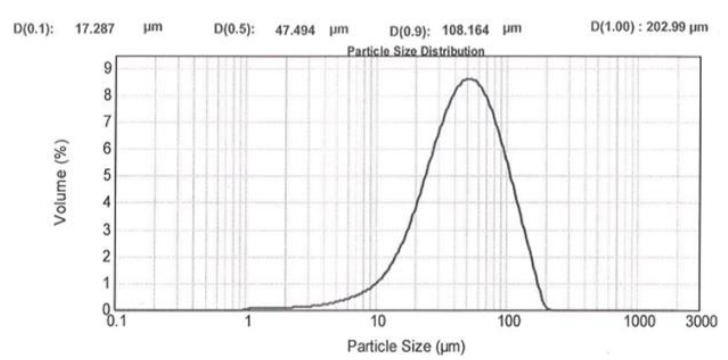

Figure 3. Particle size distribution curve of microsponges of (F3 batch).

\section{Evaluation of fluconazole microsponge loaded carbopol gel Visual inspection}

The prepared fluconazole loaded microsponge gel formulations were inspected visually for their color, texture and appearance. All prepared formulations were snow white, viscous in nature with smooth texture and of good homogeneity without lumps

\section{pH measurement}

The $\mathrm{pH}$ values of all prepared formulations were found in the range of 6.5-7, Table IV which is supposed to be suitable to pass up the threat of nuisance on application to the skin (Neha et al., 2016).

\section{Spreadability test}

Spreadability is one of the important characteristics of topical formulations and it helps to transfer correct dosage to the target site and make ease of application. Fluconazole microsponge loaded carbopol 934 forms a gel with spreadability ranges between to $7.38-11.00 \mathrm{~g} \mathrm{~cm} / \mathrm{s}$. There was a slight decrease in spreading diameters of formulations of F4-F6; this variation was might be due to increased polymer concentration in microsponge.

\section{Viscosity measurement}

Viscosity holds a major contribution in deciding the drug content and its release from prepared gel formulation. F3 carbopol gel showed approximate viscosity between 34,480$91,350 \mathrm{cPs}$. It was found that as the shear rate increased the viscosity of gel decreased (Harish et al., 2009) (Figure 4). 


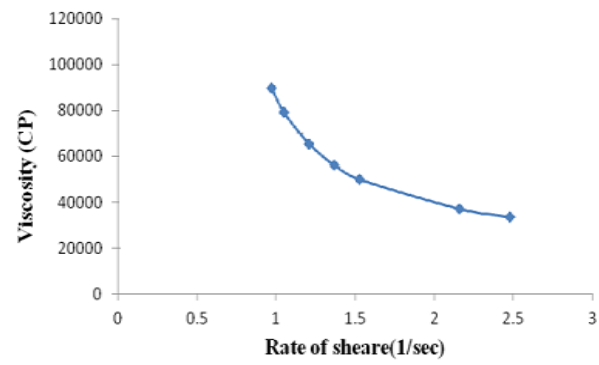

Figure 4. Viscosity versus shear rate for fluconazole microsponge gel (F3 batch).
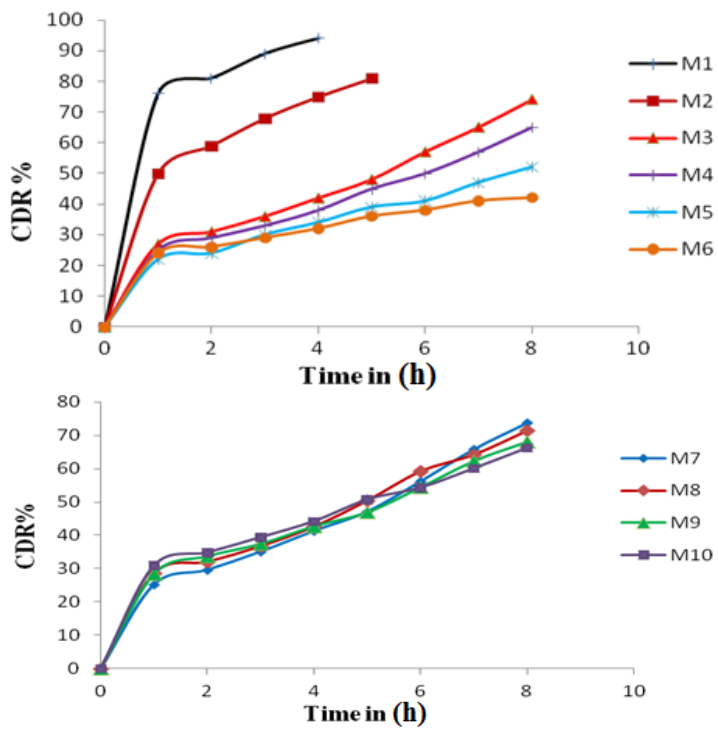

Figure 5. Dissolution profile of fluconazole microsponges F1-F6 and F7-F8

\section{In vitro drug release study}

The in vitro dissolution profile was done for fluconazole microsponge formulas (F1F10). From the in vitro release data it was noticed that the drug release was reduced from $94.10-42.70 \%$, this is due to $\mathrm{D} / \mathrm{P}$ ratio has increased i.e. the amount of polymer available was more in each formulation. It led to thickening of the polymer matrix wall, thus lesser drug release was occurring. $94.10 \%$ of drug releases were found at highest drug release (F1) within 4Hrs, while the lowest $42.70 \%$ for F6 at the end of $8 \mathrm{Hrs}$. It has been reported that by increasing the amount of PVA from batches F7 to F10, there was no significant change in the drug release pattern as compared with the F3 formulation. Cumulative drug release of all batches F1-F6 and F7-F10 (Figure 5).
According to in vitro release data formulation code F3 was selected as an optimized batch.

\section{Drug release kinetics}

The drug release kinetic data are shown in (Table III) and (Figures 6). From the graphical representation it can be understood that this layer is best fit in to Zero order kinetics which had shown a regression coefficient $\left(\mathrm{R}^{2}\right)$ of 0.9831 . The results of the in vitro release data of this layer were fitted to the Korsemeyer-Peppas equation to analyze the release pattern of the drug from the polymeric system. The value of " $n$ " was found to be more than 0.89 , indicating the drug release follows super case II transport.

\section{Effect of formulation variables Effect of external phase}

The concentration of PVA plays a vital role in the preparation of microsponges. The minimum concentration of emulsifier required for formation of uniform and stable microsponges was found to be $0.75 \% \mathrm{w} / \mathrm{v}$ of external phase. Almost, similar encapsulation efficiency was noticed formulation code F1-F6. When the concentration of emulsifier was decreased from $0.75 \%$ to $0.45 \%$ (F7) production yield, encapsulation efficiency and drug content were decreased and the formed microsponges were collapsed after 3 days. Whereas irregular microsponge was formed in the concentration of $0.6 \% \mathrm{w} / \mathrm{v}$ of emulsifier and table VII. When the concentration of emulsifier was increased to $0.9 \%$ and $1 \% \mathrm{w} / \mathrm{v}$ F9 \& F10 resulted in more foam formation and it drastically affects production yield, encapsulation efficiency and drug release behavior.

\section{Effect of $D / P$ ratio}

Increase in $\mathrm{D} / \mathrm{P}$ ratio has been found to result in an increase in production yield; while drug content, encapsulation efficiency and percent drug release were found to be decreased table VIII. The reason behind that is as $\mathrm{D} / \mathrm{P}$ ratio went on increasing, the polymer amount available for each microsponge to encapsulate the drug was more, thus rising polymer matrix wall thickness which led to an 

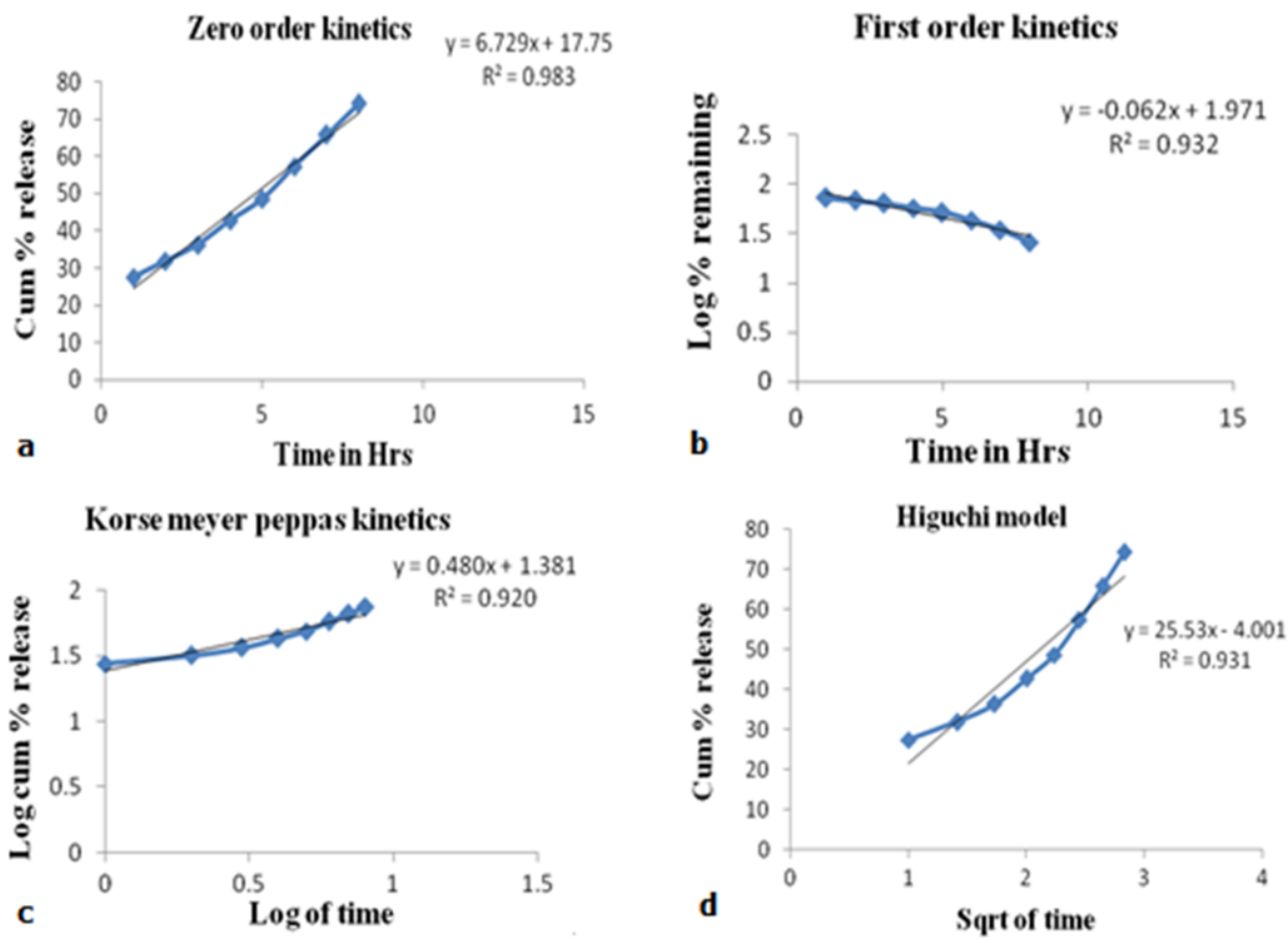

Figure 6 kinetic model a. Zero order b. First order c. Korse meyer peppas d. Higuchi

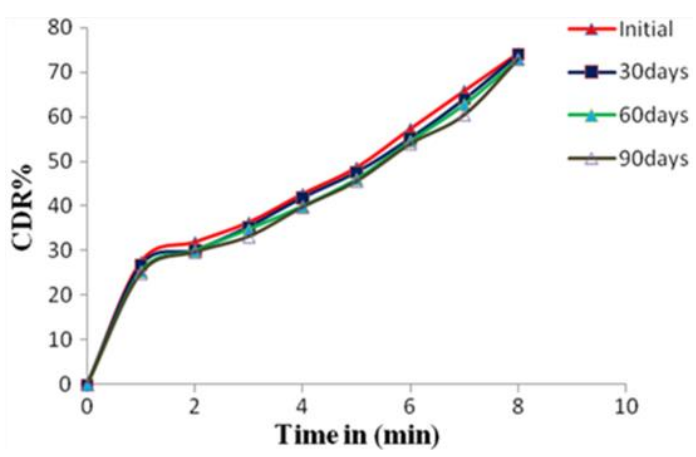

Figure 7. Drug release profile of microsponge gel during stability study

extended diffusion path and ultimately to lesser drug release

\section{Stability study}

During stability studies, the formulation was found to be a snow white, homogenous, smooth and no changes in $\mathrm{pH}$. It was also noticed that there were no changes in spreadability but slight changes in viscosity and drug release. Therefore, drug degradation was not observed. After comparative assessment of optimized formulation (F3) drug release profiles prior and after 3 months stability study, there were no significant differences in drug release profiles so, it has been concluded that the formulation was stable over the period of 3 months

\section{CONCLUSION}

The microsponge-based novel delivery system has been developed to provide once a day sustained release medication for topical delivery of Fluconazole. The method adopted was quasi-emulsion solvent diffusion; found to be simple, reproducible and rapid. Formed microsponges were a spherical shape, have high 
porosity. Different drug-polymer ratio reflected good particle size, drug content and encapsulation efficiency. Microsponge-based gel showed viscously and homogenizes preparation and in vitro drug release reflected highest regression value for zero order release model. Formulation with 1:1.5 drug-polymer ratio was found more efficient to give an extended drug release $74.20 \%$ at the end of 8h. A gel containing microsponges prepared in this study was found to be promising as newnovel delivery system offering the prolonged release of fluconazole in treating fungal infections.

\section{ACKNOWLEDGEMENT}

The authors express a deep sense of gratitude toward RMS Research labs Pvt. Ltd., Hyderabad. India and Yeluri formulations, Hyderabad, India for providing the gift samples of fluconazole and ethyl cellulose respectively.

\section{REFERNCES}

Costa P., Lobo JMS. 2001. Modeling and comparison of dissolution profiles. Europ J Pharm Sci. v13, p123-133.

D’souza JI., More HN., 2008. Topical antiinflammatory gels of fluocinolone acetonide entrapped in eudragit based microsponge delivery system. Res. J. Pharm. Technol. v1, p502-506,

Doaa A., Helal, El-Rhman DA., Abdel-Halim SA., Mohamed A., El-Nabarawi 2015. Formulation and evaluation of Fluconazole topical gel Int J Pharm Pharm Sci, v4, (Suppl 5), p176-183,

El-Houssieny B., Hamouda HM. 2010. Formulation and evaluation of clotrimazole from pluronic F127 gels. Drug discovery and therapeutics; v4(1), p33-43

Farhan JA., Mohd AA., Zeenat IK., Roop KK., Mushir A. 2008 Development and in vitro evaluatiaon of an acid buffering bioadhesive vaginal gel for mixed vaginal infections. Acta Pharm. v58: p407-419,

Harish NM., Prabhu P., Subrahmanyam EVS. 2009. Formulation and evaluation of in situ gels containing clotrimazole for oral candidiasis. Indian J Pharm Sci v71(4) p 421-427

Kilicarslan M., Baykara T., 2003. The effect of the drug/polymer ratio on the properties of verapamil hydrochloride loaded microspheres. Int. J. Pharm. v252, p99-109

Kulkarni RV., Wagh YJ., Setty CM., Sa B., 2011. Development and characterization of sodium alginate hydroxypropyl methylcellulose-polyester multilayered hydrogel membranes for drug delivery through the skin. Polym.-Plast. Technol. Eng. v50, p490-497,

Lee J-H., Park TG., Choi HK., 1999. Development of oral drug delivery system using floating microspheres. J. Microencapsul. v16 p715-729

Mine O., Erdal C., Ahmet A., 2006. Design and evaluation of colon specific drug delivery system containing flurbiprofen microsponges. Int. J. Pharm. v318, p103-117,

Neha G., Tomar N., Nagaich U., 2016. Miconazole Microsponges based topical delivery system for diaper dermatitis. Ars Pharm. v57(2): p77-87

Niethard FU., Gold MS., Solomon GS., Liu JM., Unkauf M., Albrecht HH., Elkik F., 2005. Efficacy of topical diclofenac diethylamine gel in osteoarthritis of the knee. J. Rheumatol. v32, p2384-2392,

Nokhodchi A., Jelvehgari M., Reza SM., Reza MM., 2007. Factors affecting the morphology of benzoyl peroxide microsponges. Micron v38, p834-840,

Orlu M., Cevher E., Araman A. 2006 Design and evaluation of colon specific drug delivery system containing flurbiprofen microsponges. Int JPharm. v318 p103-17,

Roaa AN., Ahmed AH., 2014 Preparation and Evaluation of Meloxicam Microsponges as Transdermal Delivery System Iraqi J Pharm Sc v23(2), p62-74

Vinod LG., Vishal DY., Rakesh PD., Prafulla BC., Swapnil DJ. 2012. 'Effect of Carbopol 934 and 940 on Fluconazole Release from Topical Gel Formulation', C.P.R. 2(2) p.487-493,

Vyas LK., Tapar KK., Laddha BH., Lahoti AO., Nema RK., 2010. Formulation and development of anti-blemish preparations using microsponge technology. J. Chem. Pharm. Res. v2, p562-571,

Vyas SP., Khar RK., 2002. Targeted and Controlled Drug Delivery Novel Carrier System, 1st ed. CBS Publication, New Delhi 


\section{S. Dineshmohan}

Won R. 1987. Method for delivering an active ingredient by controlled time release utilizing a novel delivery vehicle which can be prepared by a process utilizing the active ingredient as a porogen. U.S. Patent 4,690,825
Rizkalla ZCM., Aziz, LR., Soliman II., 2011. Invitro and in vivo evaluation of hydroxyzine hydrochloride microsponges for topical delivery. AAPS Pharm. Sci. Technol. v12, p989-1001. 